This item is the archived peer-reviewed author-version of:

\title{
Exceptional layered ordering of cobalt and iron in perovskites
}

\section{Reference:}

Lebedev Oleg I., Turner Stuart, Caignaert Vincent, Cherepanov Vladimir A., Raveau Bernard.- Exceptional layered ordering of cobalt and iron in perovskites

CHEMISTRY OF MATERIALS - ISSN 0897-4756 - 28:9(2016), p. 2907-2911

Full text (Publishers DOI): http://dx.doi.org/doi:10.1021/ACS.CHEMMATER.6B01046

To cite this reference: http://hdl.handle.net/10067/1336400151162165141 
Subscriber access provided by Loyola University Libraries

Communication

\section{Exceptional Layered Ordering of Cobalt and Iron in Perovskites.}

Oleg I Lebedev, Stuart Turner, Vincent Caignaert, Vladimir A. Cherepanov, and Bernard Raveau

Chem. Mater., Just Accepted Manuscript • DOI: 10.1021/acs.chemmater.6b01046 • Publication Date (Web): 20 Apr 2016

Downloaded from http://pubs.acs.org on April 21, 2016

\section{Just Accepted}

"Just Accepted" manuscripts have been peer-reviewed and accepted for publication. They are posted online prior to technical editing, formatting for publication and author proofing. The American Chemical Society provides "Just Accepted" as a free service to the research community to expedite the dissemination of scientific material as soon as possible after acceptance. "Just Accepted" manuscripts appear in full in PDF format accompanied by an HTML abstract. "Just Accepted" manuscripts have been fully peer reviewed, but should not be considered the official version of record. They are accessible to all readers and citable by the Digital Object Identifier (DOI囚). "Just Accepted" is an optional service offered to authors. Therefore, the "Just Accepted" Web site may not include all articles that will be published in the journal. After a manuscript is technically edited and formatted, it will be removed from the "Just Accepted" Web site and published as an ASAP article. Note that technical editing may introduce minor changes to the manuscript text and/or graphics which could affect content, and all legal disclaimers and ethical guidelines that apply to the journal pertain. ACS cannot be held responsible for errors or consequences arising from the use of information contained in these "Just Accepted" manuscripts. 
The ordering of two sorts of transition metal elements in the Bsites of the $\mathrm{ABO}_{3}$ perovskite structure is a rare phenomenon, which requires that particular conditions, such as size or valence difference, be fulfilled. For this reason in layered perovskites or derivatives containing two different transition cations, the latter are always distributed at random, except if they are elaborated as thin films, allowing super-lattices to be built. In this respect, layered oxygen deficient $\mathrm{ABO}_{3-\delta}$ perovskites containing cobalt or iron on the $B$ sites and combining rare earth and barium cations on the A sites are of great interest, due to the fact that besides the $\mathrm{Ln} / \mathrm{Ba}$ layered ordering, there exists a clear ordering of the oxygen and anionic vacancies, which may possibly generate $\mathrm{Fe} / \mathrm{Co}$ ordering. Moreover, this large family has been studied for its attractive properties, ranging from oxygen storage in view of the realization of solid oxide fuel cell cathodes (SOFC) ${ }^{1-6}$, to magnetic and magnetoresistance properties ${ }^{7}$.

The layered perovkites of the Ln-Ba-Co-O and Ln-Ba-Fe-O systems are mainly represented by two classes, the double perovskites $\mathrm{LnBaCo}_{2} \mathrm{O}_{5+\delta}{ }^{8-36}$ and $\mathrm{LnBaFe}_{2} \mathrm{O}_{5+\delta}{ }^{37-43}$, called "112" and the triple perovskites $\mathrm{LnBa}_{2} \mathrm{Fe}_{3} \mathrm{O}_{8+\delta}$, called "123" ${ }^{44-48}$. These oxides are characterized by a regular ordering of the layers of rare earth (or lanthanide Ln) and barium cations, which originates from the size difference between these two sorts of cations. Importantly, these oxygen deficient perovskites show simultaneously a specific ordering of their oxygen vacancies on the anionic sites. The latter seems to be correlated to the size of the A-site cation: the anionic vacancies are displayed in the Ln layers, whereas no oxygen deficiency is observed in the $\mathrm{BaO}$ layers. Recently, we observed a unique nanoscale ordering in quintuple perovskites $\mathrm{Ln}_{2} \mathrm{Ba}_{3} \mathrm{Fe}_{5-\mathrm{x}} \mathrm{Co}_{x} \mathrm{O}_{15-\delta}$ with $\mathrm{Ln}=\mathrm{Sm}$, Eu, Nd ${ }^{49-51}$. In the latter compounds, the ordering of the $\mathrm{Ba}$ and $\mathrm{Ln}$ layers according to the five-fold sequence "Ba-Ln-Ba-A-A-Ba", where A is a mixed layer containing $50 \%$ $\mathrm{Ba} / 50 \% \mathrm{Ln}$, suggests that the "112" $\mathrm{BaLnCo}{ }_{2-\mathrm{x}} \mathrm{Fe}_{\times} \mathrm{O}_{5+\delta}$ structure is the base of this new ordering (Ba-Ln-Ba), whereas the
"123" $\mathrm{Ba}_{2} \mathrm{LnFe}_{3} \mathrm{O}_{8+\delta}$ component is partly disordered (Ba-A-A$\mathrm{Ba})$. These results raise a first question about the possibility of complete ordering of the $\mathrm{Ln}$ and $\mathrm{Ba}$ layers in the quintuple perovskites according to the sequence "Ba-Ln-Ba-Ba-Ln-Ba" and a second question concerning the associated oxygen content and ordering of oxygen vacancies in such oxides if they exist. Bearing in mind that that the "112" structure is easily obtained for both, cobaltates and ferrates, but that the " 123 " phase is only synthesized for ferrates containing smaller cations $(\mathrm{Y}, \mathrm{Ho}, \mathrm{Dy})$ we embarked in the investigation of perovskites of the system $\mathrm{Y}-\mathrm{Ba}-\mathrm{Fe}-\mathrm{Co}-\mathrm{O}$. In the present study, we show that the oxide $\mathrm{Y}_{2} \mathrm{Ba}_{3} \mathrm{Fe}_{3} \mathrm{Co}_{2} \mathrm{O}_{13+\delta} \quad(\delta \sim 0.36)$ exhibits a unique perovskite nanostructure involving a double layered cationic ordering of both $\mathrm{Y} / \mathrm{Ba}$ and $\mathrm{Fe} / \mathrm{Co}$ layers, and simultaneously layered ordering of oxygen vacancies in the quintuple perovskite matrix, corresponding to the ideal intergrowth $\left[\mathrm{YBaCO}_{2} \mathrm{O}_{5}\right]\left[\mathrm{YBa}_{2} \mathrm{Fe}_{3} \mathrm{O}_{8}\right]$, with oxygen excess $(0.36 \mathrm{O})$ sandwiched between one cobalt and one $\mathrm{Fe}$ layer at the level of the $\mathrm{Y}$ layer.

Similarly to $\mathrm{Ln}_{2} \mathrm{Ba}_{3} \mathrm{Fe}_{5-\mathrm{x}} \mathrm{Co}_{x} \mathrm{O}_{15-\delta}$ phases with $\mathrm{Ln}=\mathrm{Nd}, \mathrm{Sm}$, Eu ${ }^{49-}$ ${ }^{51}$, the presence of cobalt in the $Y$ phase plays an important role for the stabilization of the ordered quintuple perovskite structure. However, the chemical analysis of our sample of nominal cationic composition " $\mathrm{Y}_{2} \mathrm{Ba}_{3} \mathrm{Fe}_{3} \mathrm{CO}_{2}$ " prepared in air shows that its oxygen content is significantly smaller. In fact, we prefer to formulate it as $\mathrm{Y}_{2} \mathrm{Ba}_{3} \mathrm{Fe}_{3} \mathrm{Co}_{2} \mathrm{O}_{13+\delta}$, with $\delta_{\sim} 0.36$, for structural reasons that will be developed further. The powder X-ray diffraction pattern of this phase (Fig.S1 in the supporting information) shows that similar to the $\mathrm{Sm}$, Eu and Nd-homologues, the peaks can be indexed in a cubic perovskite, but that differently from the latter they are broader, suggesting a possible tetragonal symmetry involving order-disorder phenomena. Based on these observations, electron diffraction (ED) investigation of this oxide was performed, showing that two sorts of crystals with a closely related perovskite structure were coexisting. A large number of crystals exhibit a perfectly ordered tetragonal perovskite structure characterized by the presence of 
five-fold superstructure reflections only along one $a_{p}$ direction with respect to the basic cubic sub-cell, corresponding to the " $a_{p} \times a_{p} \times 5 a_{p}$ "cell parameters (Fig.1a). For another part of the crystals, the ED patterns (Fig.1b) still show the tetragonal perovskite structure, but the superstructure reflections along one $a_{p}$ direction show streaks and do not correspond to a welldefined quintupling of the cell parameters, indicating the existence of disorder along that direction with possible " $a_{p} x a_{p} x$ nap" short range orderings.

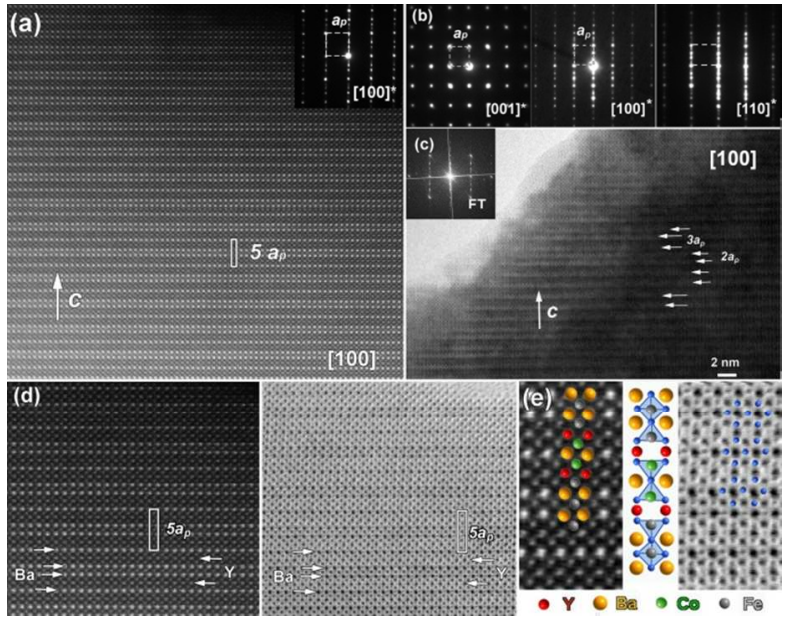

Figure 1. $\mathrm{Y}_{2} \mathrm{Ba}_{3} \mathrm{Fe}_{3} \mathrm{Co}_{2} \mathrm{O}_{13+\delta}$ : (a) [100]HAADF-STEM image of perfect ordered $\mathrm{Y}_{2} \mathrm{Ba}_{3} \mathrm{Fe}_{3} \mathrm{Co}_{2} \mathrm{O}_{13.5}$ structure and corresponding $\mathrm{ED}$ pattern; (b) ED patterns along main zone axis of disordered $\mathrm{Y}_{2} \mathrm{Ba}_{3} \mathrm{Fe}_{3} \mathrm{Co}_{2} \mathrm{O}_{13.36}$ structure: [001]*, [100]* and [110]*. Note the presence of streaks along the [001] direction; (c) [100] HRTEM image and corresponding FT pattern of the disordered Y2Ba3Fe3Co2O13.36 structure containing numbers of stacking faults along the c-axis marked by white arrows; (d) HAADFSTEM and simultaneously acquired ABF-STEM images along the [100] zone axis of the ordered $\mathrm{Y}_{2} \mathrm{Ba}_{3} \mathrm{Fe}_{3} \mathrm{Co}_{2} \mathrm{O}_{13.50}$; (e) enlargement of HAADF-STEM and ABF-STEM images and overlaid heavy atoms position ( Y-red, Ba-yellow, Co-green and Fe-gray) and light atoms (O-blue) in HAADF-STEM and ABF-STEM images respectively. The corresponding structural model is given as insert. Note that oxygen vacancies are located between $\mathrm{Y}$ columns along a-axis and that the oxygen positions close to the $\mathrm{Y}$ columns are severely displaced with respect to the standard octahedral symmetry positions along the c-axis.

The five-fold " $a_{p} \times a_{p} \times 5 a_{p}$ " superstructure observed for the perfectly ordered crystals, suggests that the latter exhibit a quintuple layer ordering similar to that previously shown for other members, $\mathrm{Ln}_{2} \mathrm{Ba}_{3} \mathrm{Fe}_{5-\mathrm{x}} \mathrm{Co}_{x} \mathrm{O}_{15-\delta}{ }^{49-51}$. However, differently from the latter, this oxide is not chemically twinned at a nanoscale. One indeed observes five-fold superstructure reflections only along one $a_{p}$ direction with respect to the basic cubic sub-cell. This feature is corroborated by the [100] high resolution transmission electron microscopy (HRTEM) images (Fig. 1a) which show a quite regular 1:1 stacking of double and triple perovskite cells along $c$ alternately and confirm the absence of $90^{\circ}$ oriented twinned domains, contrary to the other Lnhomologues of the series ${ }^{[49]}$. The [100] high angle annular dark field scanning TEM (HAADF-STEM) image (Fig.1d) clearly shows that the nature and the stacking of the $\mathrm{Ba}$ and $\mathrm{Y}$ layers is also significantly different from the other Ln-quintuple perovskites. One observes only two sorts of layers (very bright dots and much less bright dots corresponding to $B a$ and $Y$ respectively) with the stacking sequence "Y-Ba-Ba-Y-Ba-Y" along the $c$-axis. Instead, the other Ln-quintuple perovskites exhibit three sorts of layers $\mathrm{Ln}, \mathrm{Ba}$ and mixed $\mathrm{A}\left(\mathrm{Ba}_{0.5} \mathrm{Ln}_{0.5}\right)$, with the stacking sequence "Ln-Ba-A-A-Ba-Ln". This suggests that $\mathrm{Y}_{2} \mathrm{Ba}_{3} \mathrm{Fe}_{3} \mathrm{Co}_{2} \mathrm{O}_{13+\delta}$ can be described as an intergrowth of a triple (Y-Ba-Ba-Y) and a double (Y-Ba-Y) perovskite.

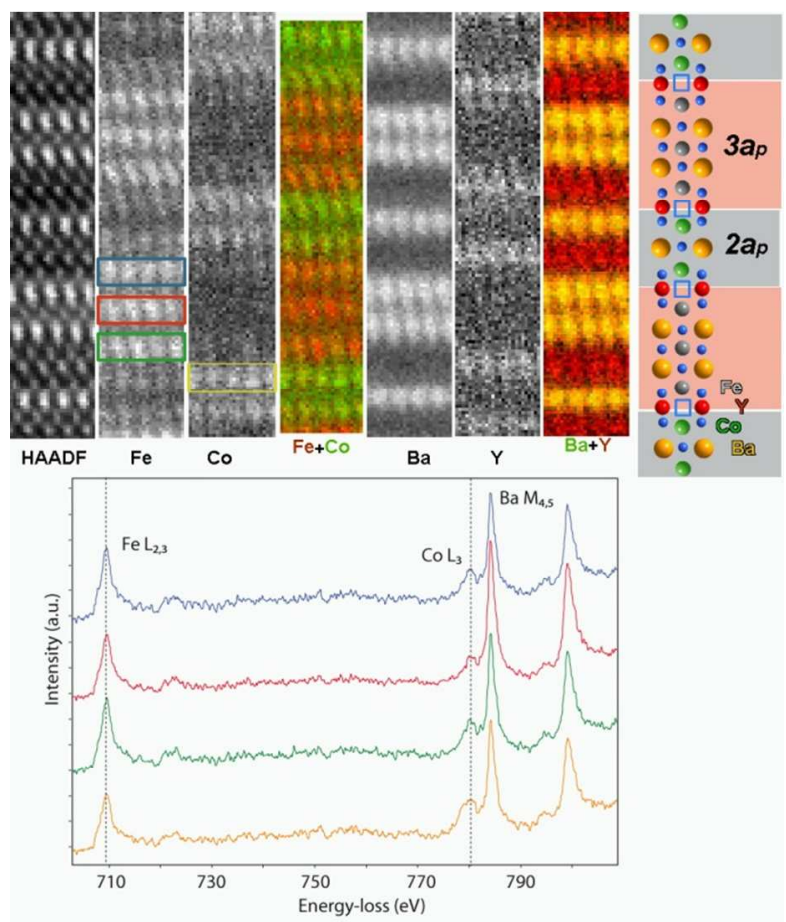

Figure 2. (a) EELS elemental mapping of ordered $\mathrm{Y}_{2} \mathrm{Ba}_{3} \mathrm{Fe}_{3} \mathrm{Co}_{2} \mathrm{O}_{13.50}$ : overview HAADF-STEM image, $\mathrm{Fe}-\mathrm{L}_{2,3}$ map , Co- $\mathrm{L}_{2,3}$ map , Ba-M ${ }_{4,5}$ map , O-K map. Colour overlays with $\mathrm{Fe}$ in red and $\mathrm{Co}$ in green and also overlays with $\mathrm{Y}$ in red and $\mathrm{Ba}$ in green, together with a structural model with $\mathrm{Y}$ in red, $\mathrm{Fe}$ in grey, $\mathrm{Ba}$ in yellow, $\mathrm{Co}$ in green and $\mathrm{O}$ in blue. (b) EELS fine structure of $\mathrm{Y}_{2} \mathrm{Ba}_{3} \mathrm{Fe}_{3} \mathrm{Co}_{2} \mathrm{O}_{13.50}$ obtained from the regions indicated as $\mathrm{Fe}$ and $\mathrm{Co}$ in the mapping.

This perfect ordering between the $\mathrm{Ba}$ and $\mathrm{Y}$ layers is clearly confirmed by elemental electron energy loss spectroscopy (EELS) mapping (Fig.2a). One indeed observes that pure double Ba-layers $(\mathrm{Ba} 2)$ are stacked with single Ba-layers (Ba1) along $\mathrm{c}$ and that single $\mathrm{Y}$-layers are sandwiched between one double and one single Ba-layer. But the most remarkable feature deals with the ordering of $\mathrm{Fe}$ and $\mathrm{Co}$ in the form of layers: for the first time a perfect stacking of triple Fe layers $(\mathrm{Fe} 3)$ with double Co layers ( $\mathrm{Co} 2)$ within a perovskite matrix (Fig.2a) is observed, in spite of the similar size of $\mathrm{Co}$ and $\mathrm{Fe}$ and of their ability to accommodate the same type of coordination. Moreover, one observes that the double $\mathrm{Ba} 2$ layers are sandwiched between the triple $\mathrm{Fe} 3$ layers, whereas the single $\mathrm{Ba} 1$ layers are sandwiched between the double $\mathrm{Co} 2$ layers. This double cationic ordering corresponds to the following stacking sequence along c: "Fe-Ba-Fe-Ba- Fe-Y-Co-Ba-Co-Y-Fe"

This exceptional type of cationic ordering suggests that the oxygen stoichiometry may play a role in its stabilization, resulting from the alternate stacking of double perovskite slices 
$\mathrm{YBaCo}_{2} \mathrm{O}_{5}$ (Fig.3a) and triple perovskite slices with the ideal composition $\mathrm{YBa}_{2} \mathrm{Fe}_{3} \mathrm{O}_{8}$ (Fig.3b). The ideal composition of such a triply ordered perovskite, $\mathrm{Y}_{2} \mathrm{Ba}_{3} \mathrm{Fe}_{3} \mathrm{Co}_{2} \mathrm{O}_{13}$, close to that observed experimentally, $\mathrm{Y}_{2} \mathrm{Ba}_{3} \mathrm{Fe}_{3} \mathrm{Co}_{2} \mathrm{O}_{13+\delta}$, with $\delta_{\sim} 0.36$ supports this hypothesis. In order to understand the distribution of oxygen vacancies in the structure, annular bright field STEM (ABF-STEM) imaging has been carried out. Bearing in mind that the brightest big dots on the HAADF-STEM image correspond to barium (Fig. 1d,f) and that the reverse contrast is obtained on the ABF-STEM image (Fig.1 e,g) one can easily see from the enlarged ABF-STEM image (Fig.1g) that at the level of the $\mathrm{Ba}$ layers (largest dark dots) the anionic sites between two barium cations are fully occupied by oxygen (smallest well resolved dark dots), forming stoichiometric (001) BaO layers. In contrast, at the level of the $\mathrm{Y}$ layers (intermediate size dark dots on the ABF-STEM image) the anionic sites between two yttrium cations are very weakly occupied (weak and diffuse grey spots) forming $\mathrm{YO}_{\delta / 2}$ layers, with partially occupied anionic sites (ס 0.36). These observations demonstrate that the $\mathrm{Y}_{2} \mathrm{Ba}_{3} \mathrm{Fe}_{3} \mathrm{Co}_{2} \mathrm{O}_{13+\delta}$ structure corresponds to the perfect intergrowth $\left[\mathrm{YBa}_{2} \mathrm{Fe}_{3} \mathrm{O}_{8}\right]\left[\mathrm{YBaCo}_{2} \mathrm{O}_{5}\right]$ of the "123" ferrite and "112" cobaltate (Fig.3c), with oxygen excess $(\delta)$ distributed at the boundary of the two blocks, sandwiched between $\mathrm{FeO}_{5}$ and $\mathrm{CoO}_{5}$ pyramids.

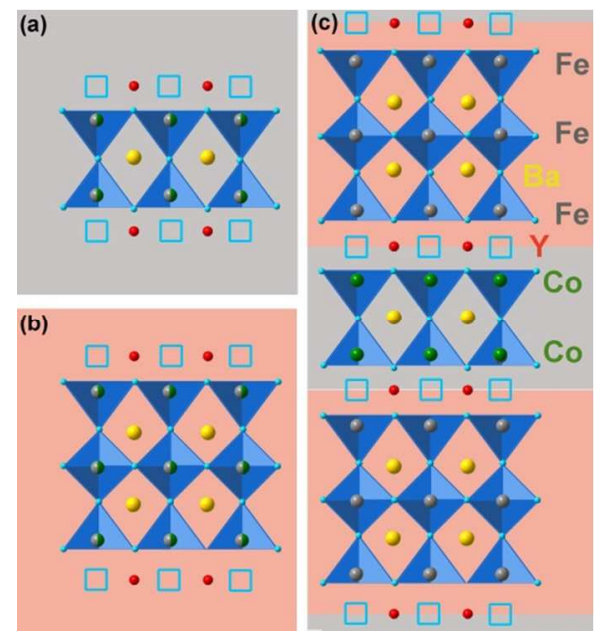

Figure 3. Structural models represented along the [100] zone axis of (a) $\mathrm{YBaCo}_{2} \mathrm{O}_{5}$ (b) - $\mathrm{YBa}_{2} \mathrm{Fe}_{3} \mathrm{O}_{8}$ and (c)-ideal $\mathrm{Y}_{2} \mathrm{Ba}_{3} \mathrm{Fe}_{3} \mathrm{Co}_{2} \mathrm{O}_{13}$

The unique ordering of the $\mathrm{Co}$ and Fe layers in the structure suggests the possibility of phase disproportionation of $\mathrm{Y}_{2} \mathrm{Ba}_{3} \mathrm{Fe}_{3} \mathrm{Co}_{2} \mathrm{O}_{13+\delta}$ into the two compounds "112" $\mathrm{YBaCo}_{2} \mathrm{O}_{5}$ and "123" $\mathrm{YBa}_{2} \mathrm{Fe}_{3} \mathrm{O}_{8}$, due the fact that the energy which characterizes the structure of these two compounds should be very close to that of their intergrowth and in any case would be highly sensitive to the temperature of synthesis. This viewpoint is confirmed by the fact that a substantial number of crystals exhibits a disordered stacking of the layers along $c$ (Fig. 1 b-c). In fact, the HAADF images of these crystals (Fig.4a) show that for most of them, the "112" $\mathrm{YBaCo}_{2} \mathrm{O}_{5}$ phase appears as stacking defects $\left(c \sim 2 a_{p}\right)$ distributed at random with respect to the majority intergrowth phase $\left(\mathrm{c} \sim 5 \mathrm{a}_{\mathrm{p}}\right)$. The "112" $\mathrm{YBaCo}_{2} \mathrm{O}_{5}$ excess that appears in such disordered crystals is chemically compensated by the formation of some "123" triple perovskite(c $3 a_{p}$ ) $\mathrm{YBa}_{2} \mathrm{Fe}_{3} \mathrm{O}_{8}$ crystals (Fig. $4 \mathrm{~b}$ ).

The formula of this oxide deduced from the chemical analysis raises the issue of the $\mathrm{Co}$ and $\mathrm{Fe}$ valence. Bearing in mind that divalent cobalt should be oxidized by tetravalent iron according to the equation: $\mathrm{Fe}^{4+}+\mathrm{Co}^{2+}{ }_{\rightarrow} \mathrm{Fe}^{3+}+\mathrm{Co}^{3+}$, this oxide should be formulated $\mathrm{Y}_{2} \mathrm{Ba}_{3} \mathrm{Fe}^{\prime \prime \prime}{ }_{3} \mathrm{Co}^{\prime \prime \prime}{ }_{1.72} \mathrm{Co}_{0.28} \mathrm{O}_{13.36}$. In order to understand the charge distribution in this oxide, spatially resolved EELS spectra containing the $\mathrm{Fe}-\mathrm{L}_{2,3}$ and $\mathrm{Co}-\mathrm{L}_{2,3}$ edges have been performed on perfectly ordered crystals (Fig.2b). It is clear from the position of both the $\mathrm{Fe}-\mathrm{L}_{2,3}$ and $\mathrm{Co}_{\mathrm{L}} \mathrm{L}_{2,3}$ EELS edges that both $\mathrm{Fe}$ and $\mathrm{Co}$ are in the trivalent state. The absence of $\mathrm{a}$ clear pre-peak to the $\mathrm{Fe}_{\mathrm{L}}$ edge indicates a deviation from a perfect octahedral coordination towards a lower coordination for iron, most likely caused by the presence of oxygen vacancies 49 . The absence of $\mathrm{Co}^{2+}$ shows that the oxygen stoichiometry of the perfectly ordered phase is slightly different from that observed from the chemical analysis, leading to the chemical formula $\mathrm{Y}_{2} \mathrm{Ba}_{3} \mathrm{Fe}^{\text {III }}{ }_{3} \mathrm{Co}_{0}{ }_{2}{ }_{2} \mathrm{O}_{13.50}$. This difference can be explained by the fact that $\mathrm{Co}^{2+}$ is contained in the "112"- $\mathrm{YBaCo}_{2} \mathrm{O}_{5}$ defects of the disordered crystals. In other words, this suggests that the perfect ordering of $\mathrm{Co}$ and $\mathrm{Fe}$ in the form of layers is strongly dependent on the oxygen stoichiometry, the presence of $\mathrm{Co}^{2+}$ favoring the stacking disorder by formation of 112-type defects (Fig.4a).

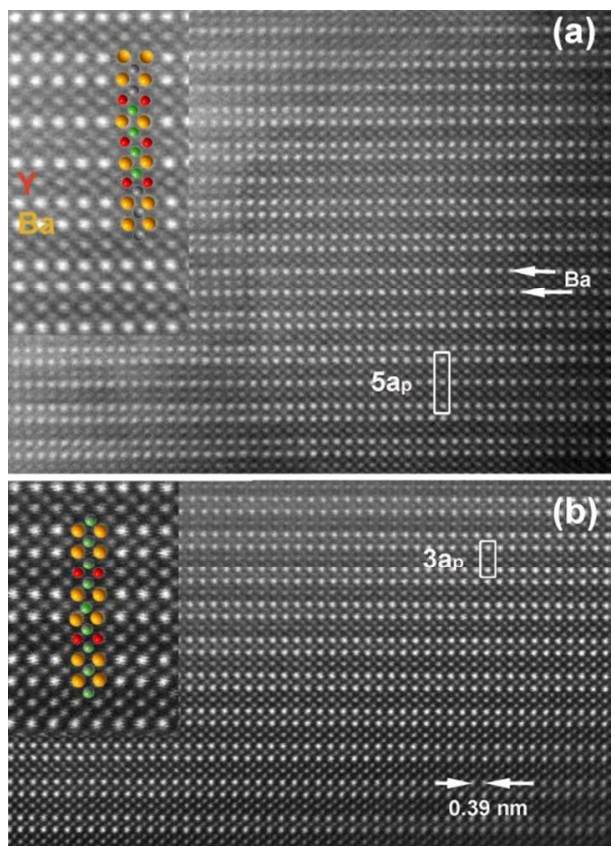

Figure 4. HAADF-STEM images along the [100] zone axis orientation, showing different types of defect structures : (a) unit cell contrast with "5ap perovskite periodicity" along the c-axis of $\mathrm{Y}_{2} \mathrm{Ba}_{3} \mathrm{Fe}_{3} \mathrm{Co}_{2} \mathrm{O}_{13.50}$ containing intergrowth 112-type defects stacked along the c-axis; (b) area of "123" triple perovskite (c $3 \mathrm{ap}$ ) $\mathrm{YBa}_{2} \mathrm{Fe}_{3} \mathrm{O}_{8}$ crystals. Enlargements and overlay models are given as insert.

In conclusion, the possibility of layered ordering between two transition metal cations with the same oxidation state $(+3)$ and similar size $(0.61-0.64 A)$ in the $B$ sites of a perovskite matrix is shown for the first time. This structural behavior of 
$\mathrm{Y}_{2} \mathrm{Ba}_{3} \mathrm{Fe}_{3} \mathrm{Co}_{2} \mathrm{O}_{13.36}$ is different from the other members of the series with $\mathrm{Ln}=\mathrm{Nd}, \mathrm{Sm}$, Eu, which also exhibit all the same " $\mathrm{ap}_{\mathrm{p}}$ $x a_{p} \times 5 a_{p}$ " supercell, but for which no Fe/Co ordering was previously detected. The appearance of an ordered stacking of Co and $\mathrm{Fe}$ layers for $\mathrm{Y}$ only can be explained by the combination of two factors. The first one deals with the size difference between barium and the rare earth and the second one concerns the oxygen stoichiometry/ordering. In fact, the ordered "123" $\mathrm{YBa}_{2} \mathrm{Fe}_{3} \mathrm{O}_{8}$ structure is the foundation stone of this long range ordering, since it has the highest stability and can only be obtained for $\mathrm{LnBa}_{2} \mathrm{Fe}_{3} \mathrm{O}_{8}$ oxides with small rare earths ( $\mathrm{Ln}=\mathrm{Dy}$, $\mathrm{Ho}, \mathrm{Er}, \mathrm{Y})^{45-48}$, whereas for larger size ( $\mathrm{Ln}=\mathrm{Nd}, \mathrm{Sm}$, Eu) partial oxygen ordering leading to a cubic or pseudo-cubic symmetry of the ferrate is obtained ${ }^{45,52}$.The absence of Co/Fe mixing within the triple iron layers at the benefit of separated double cobalt layers is in agreement with the fact that $\mathrm{YBa}_{2} \mathrm{Co}_{3} \mathrm{O}_{8}$ is not obtained in normal synthesis conditions and that the level of Co for $\mathrm{Fe}$ substitution in the triple perovskite $\mathrm{YBa}_{2} \mathrm{Fe}_{3} \mathrm{O}_{8}$ was shown to be smaller than $50 \%$,even in special synthesis conditions using soft chemistry synthesis and higher oxygen pressure of one atmosphere ${ }^{[53]}$. The high stability of double perovskites $\mathrm{YBaCO}_{2} \mathrm{O}_{5+\delta}$ supports also this ability of $\mathrm{Co}$ to form double layers rather than to be distributed at random with Fe. These results open the road to the investigation of various superlattices in bulk perovskites and derivatives for the generation of new physical properties.

The oxide $\mathrm{Y}_{2} \mathrm{Ba}_{3} \mathrm{Fe}_{3} \mathrm{Co}_{2} \mathrm{O}_{13.36}$ was synthesized by solid state reaction in air, using $\mathrm{Y}_{2} \mathrm{O}_{3}$ or $\mathrm{Eu}_{2} \mathrm{O}_{3}, \mathrm{Fe}_{2} \mathrm{O}_{3}$, " $\mathrm{CoO}_{1.36}$ " and $\mathrm{Ba}$ $\mathrm{CO} 3$ as starting materials. The compounds were first intimately mixed in required proportions, and de-carbonated at $1000^{\circ} \mathrm{C}$ for $24 \mathrm{hrs}$. The mixtures were then ground and pressed in the form of bars and heated at $1100^{\circ} \mathrm{C}$ for $48 \mathrm{hrs}$. The oxygen content in the single phase oxide was determined by both, iodometric titration and thermogravimetric analysis TGA (STA 409PC, Netzsch Gmbh) (see supporting information S3).

TEM, including HRTEM and ED experiments were carried out on a FEI Tecnai G2 30 UT microscope operated at $300 \mathrm{kV}$. HAADF-STEM and ABF-STEM were performed on a JEOL ARM-200F cold FEG double aberration corrected microscope operated at $200 \mathrm{kV}$ and equipped with a large solid-angle CENTURIO EDX detector. EELS experiments were performed on a Titan "cubed" double aberration corrected electron microscope equipped with a high-brightness gun, electron monochromator excited to provide $250 \mathrm{meV}$ energy resolution and a high resolution EELS spectrometer (Gatan Enfinium) operated at $120 \mathrm{kV}$ for the EELS. For experimental setting see supporting information S2.

\section{ASSOCIATED CONTENT}

Supporting Information. Additional experimental data and XRD data (PDF).This material is available free of charge via the Internet at http://pubs.acs.org."

\section{AUTHOR INFORMATION}

\section{Corresponding Author}

*E-mail: oleg.lebedev@ensicaen.fr

\section{Author Contributions}

a,b,c These authors contributed equally.

\section{ABBREVIATIONS}

TEM, transmission electron microscopy; HAADF-STEM, high angle annular dark field scanning TEM; ED, electron diffraction; ABF-STEM, annular bright field scanning TEM. EELS,electron energy loss spectroscopy .

\section{REFERENCES}

(1) Chang, A.; Skinner, S.J.; Kilner, J.A. Electrical Properties of $\mathrm{GdBaCo}_{2} \mathrm{O}_{5+\mathrm{x}}$ for ITSOFC Application Solid State Ionics 2006, 177, 2009.

(2) Tsipis, E.V.; Kharton, V.V. Electrode Materials and Reaction Mechanisms in Solid Oxide Fuel Cells: a Brief Review. II. Electrochemical Behavior vs. Materials Science Aspects, J. Solid State Electrochem. 2008, 12, 1367.

(3) Kim, J.-H.; Manthiram A. $\mathrm{LnBaCo}_{2} \mathrm{O}_{5+\delta}$ Oxides as Cathodes for Intermediate-Temperature Solid Oxide Fuel Cells J. Electrochem. Soc. 2008, 155, B385.

(4) Motohashi, T.; Ueda, T.; Masubuchi, Y.; Takiguchi, M.; Seyotama, T.; Oshima, K.; Kikkawa, S. Remarkable Oxygen Intake/Release Capability of $\mathrm{BaYMn}_{2} \mathrm{O}_{5+\delta}$ : Applications to Oxygen Storage Technologies Chem. Mater. 2010, 22, 3192.

(5) Świerczek, K. Physico-Chemical Properties of $\mathrm{Ln}_{0.5} \mathrm{~A}_{0.5} \mathrm{Co}_{0.5} \mathrm{Fe}_{0.5} \mathrm{O}_{3-\delta}$ (Ln: La, Sm; A: Sr, Ba) Cathode Materials and Their Performance in Electrolyte-Supported Intermediate Temperature Solid Oxide Fuel Cell J. of Power Sources 2011, 196, 7110 .

(6) Chen, D.;. Wang, F; Shi, H.; Ran, R.; Shao, Systematic Evaluation of $\mathrm{Co}$-free $\mathrm{LnBaFe}_{2} \mathrm{O}_{5+\delta}(\mathrm{Ln}=$ Lanthanides or $\mathrm{Y})$ Oxides Towards the Application as Cathodes for Intermediate-Temperature Solid Oxide Fuel CellsZ. Electrochimica Acta 2012, 78, 466.

(7) Raveau, B., Motin Seikh, M.; Cobalt Oxides : From crystal Chemistry to Physics, Wiley-VCH, 2012.

(8) Barbey, L.; Nguyen, N.; Caignaert, V.; Studer, F .;B. Raveau, Spin State and Variation of the Spin Orientation of Co(III) in the 112Type Phase $\mathrm{YBa}\left(\mathrm{Co}_{2-\mathrm{x}} \mathrm{CU}_{x}\right) \mathrm{O}_{5}$ J. Solid State Chem. 1994, 112, 148.

(9) Maignan, A.; Martin, C.; Pelloquin, D.; Nguyen, N.; Raveau, B. Structural and Magnetic Studies of Ordered Oxygen-Deficient Perovskites $L n \mathrm{BaCO}_{2} \mathrm{O}_{5+\delta}$, Closely Related to the "112" Structure $J$. Solid State Chem. 1999, 142, 247-260.

(10) Burley, J. C.; Mitchell, J. F.; Short, S.; Miller, D.; Tang, Y. Structural and Magnetic Chemistry of $\mathrm{NdBaCo}_{2} \mathrm{O}_{5+\delta} J$. Solid State Chem. 2003, 170, 339-350.

(11) Vogt, T.; Woodward, P. M.;Karen, P.;Hunter, B. A.; Henning, P. ; Moodenbaugh, A. R. Low to High Spin-State Transition Induced by Charge Ordering in Antiferromagnetic $\mathrm{YBaCo}_{2} \mathrm{O}_{5}$ Phys.Rev. Lett. 2000, 84, 2969.

(12) Fauth, F.; Suard, E.; Caignaert, V.; Mirebeau, I.; Keller, L. Interplay of Structural, Magnetic and Transport Properties in the Layered Co-based Perovskite $\mathrm{LnBaCo}_{2} \mathrm{O}_{5}(\mathrm{Ln}=\mathrm{Tb}$, Dy, Ho) Eur. Phys. J. 2001, 21, 163.

(13) Barbey, L.; Nguyen, N.; Ducouret, A.; Caignaert, V.; Grenèche, J. M.; Raveau, B. Magnetic Behavior of the "112" Type Substituted Cuprate $\mathrm{YBaCoCu}_{1-x} \mathrm{Fe}_{x} \mathrm{O}_{5}$ J. Solid State Chem. 1995, $115,514-520$.

(14) Suard, E;. Fauth, F.; Caignaert, V.; Mirebeau, I. ; Baldinozzi, G. Charge ordering in the layered Co-based perovskite $\mathrm{HoBaCo}_{2} \mathrm{O}_{5}$ Phys. Rev. B 2000, 61, R11871.

(15) Rautama, E. L. ; . Boullay, P; Kundu, A. K., Caignaert, V.; Pralong, V.; Karpinnen, M.; Raveau, B. Cationic Ordering and Microstructural Effects in the Ferromagnetic Perovskite La0.5Ba0.5CoO3: Impact Upon Magnetotransport Properties Chem. Mater. 2008, 20, 2742.

(16) Kundu, A. K. ; Rautama, E. L.; Boullay, P.; Caignaert, V. ; Pralong, V.; Raveau, B. Spin-Locking Effect in the Nanoscale Ordered Perovskite Cobaltite $\mathrm{LaBaCo}_{2} \mathrm{O}_{6}$ Phys. Rev. B 2007, 76, 184432.

(17) Nakajima, T.; Ichihara, M.; Ueda, Y. New A-site Ordered Perovskite Cobaltite $\mathrm{LaBaCo}_{2} \mathrm{O}_{6}$ : Synthesis, Structure, Physical Property and Cation Order-Disorder Effect J. Phys. Soc. Jpn. 2005, 74, 1572-1577. 
(18) Pralong, V.; Caignaert, V.; Hébert, S.; Maignan, A.; Raveau, B. Electrochemical Oxidation and Reduction of the $\mathrm{La}_{0.2} \mathrm{Sr}_{0.8} \mathrm{CoO}_{3-\mathrm{d}}$ Phases: Control of Itinerant Ferromagnetism and Magnetoresistance. Solid State Ionics 2006, 177, 815-820.

(19) Seikh, M. M.; Pralong, V.; Lebedev, O.I.; Caignaert, V.; Raveau, B. The Ordered Double Perovskite PrBaCo2O6: Synthesis, Structure and Magnetism J. Appl. Phys. 2013, 114, 013902.

(20) Conder, K.; Pomjakushina, E.; Pomjakushin, V.; Stingaciu, M.; Streule, S.; Podlesnyak, A.; Oxygen Isotope Effect on MetalInsulator Transition in Layered Cobaltites $\mathrm{RBaCo}_{2} \mathrm{O}_{5.5}(\mathrm{R}=\mathrm{Pr}$, Dy, Ho and Y) Phys.: Condens. Matter 2005, 17, 5813.

(21) Mevs , H.; Muller-Buschbaum, H. Neue Oxometallate vom $\mathrm{BaCuSm}_{2} \mathrm{O}_{6}$-Typ: $\mathrm{BaCoHo}_{2} \mathrm{O}_{5}, \mathrm{BaCoYb}_{2} \mathrm{O}_{5}$ und vom BaNiLn2O5Typ: BaCoEr2O5 Z. Anorg. Allg. Chem. 1989, 574,172-176.

(22) Frontera, C. Garcia-Munoz, J.L;. Carillo, A.E.; Ritter, C.; Marero, D. ; Caneiro, A. Structural and magnetic study of $\mathrm{PrBaCo}_{2} \mathrm{O}_{5+\delta}(\delta \simeq 0.75)$ cobaltite Phys.; Rev. B 2004, 70, 184428.

(23) Streule, S.; Podlesnyak, A. ; Sheptyakov, D.; Pomjakushina, E.; Stingaciu, M.; Conder, K.; Medarde, M.; Patrakiev, M. V.; Leodinov, I. A.;. Kozhenikov, V. L ; Mesot, J. High-temperature Order-disorder Transition and Polaronic Conductivity in $\mathrm{PrBaCo}_{2} \mathrm{O}_{5.48}$ Phys. Rev. B 2006, 73, 094203.

(24) Frontera, C.; Garcia-Munoz, J. L.; Llobet, A.; Aranda, M. A. Selective Spin-State Switch and Metal-Insulator Transition in $\mathrm{GdBaCO}_{2} \mathrm{O}_{5.5}$ Phys. Rev. B 2002, 65, 180405

(25) Kusuya, H.; Machida, A.; Moritomo, Y.; Kato, K.; Nishibori, E.; Takata, M.; Sakata, M.; Nakamura, A. Structural Change at MetalInsulator Transition of $\mathrm{Tb}_{2} \mathrm{Ba}_{2} \mathrm{Co}_{4} \mathrm{O}_{11}$ J. Phys. Soc. Jpn. 2001, 70, $3577-3580$

(26) Podlesnyak, A.; Streule, S.; Conder, K.; Pomjakushina, E.; Mesot, J.; Mirmelstein, A.; Schützendorf, P.; Lengsdorf, R.; AbdElmeguid, M. Pressure effects on crystal structure, magnetic and transport properties of layered perovskite $\mathrm{TbBaCo}_{2} \mathrm{O}_{5.5}$ Physica $B$ 2006, 378, 537-538.

(27) Plakhty, V. P.;. Chernenkov, Y. P; Barilo, S. N.; Podlesnyak, E.; Pomjakushina, E.; Moskvin, E. V.;. Gavrilov, S. V Spin Structure and Magnetic Phase Transitions in $\mathrm{TbBaCo}_{2} \mathrm{O}_{5.5}$ Phys. Rev. B 2005, 71,214407

(28) Jorgensen, J.; Keller, L. Magnetic Ordering in $\mathrm{HoBaCo}_{2} \mathrm{O}_{5.5}$ Phys. Rev. B 2008, 77, 024427.

(29) Moritomo, Y.; Akimito, Y.; Takeo, M.; Machida, A ; Nishibori, E.; Takata, M.; Sakata, M.; Ohoyama, K.; Nakamura , A. Metal-Insulator Transition Induced by a Spin-State Transition in $\mathrm{TbBaCo}_{2} \mathrm{O}_{5+\delta}(\delta=0.5)$ Phys. Rev. B 2000, 61, R13325.

(30) Khalyavin, D. D.; Argyriou, D. N; Amann, U.; Yaremchenko, A. A.; Kharton, V. V. Spin-state ordering and magnetic structures in the cobaltites $\mathrm{YBaCo} 2 \mathrm{O} 5+\delta(\delta=0.50$ and 0.44) Phys. Rev. B 2007, 75, 134407.

(31) Akahoshi, D.; Ueda , Y. Oxygen Nonstoichiometry, Structures, and Physical Properties of $\mathrm{YBaCo}_{2} \mathrm{O}_{5+x}(0.00 \leq x \leq 0.52) J$. Solid State Chem. 2001, 156, 355-363.

(32) Fauth, F.; Suard, E.; Caignaert, V.; Mirebeau, I. Spin-State Ordered Clusters in the Perovskite $\mathrm{NdBaCo}_{2} \mathrm{O}_{5.47}$ Phys. Rev. B 2002, 66,184421

(33) Seikh, M. M.; Simon, C.; Caignaert, V.; Pralong, V.; Lepetit, B.; Boudin, S. ; Raveau, B. New Magnetic Transitions in the Ordered Oxygen-Deficient Perovskite $\mathrm{LnBaCo}_{2} \mathrm{O}_{5.50+\mathrm{d}}$ Chem. Mater. 2008, 20, 231-238.

(34) Taskin, A. A.; Lavrov, A. N.;. Ando, Y Transport and Magnetic Properties of $\mathrm{GdBaCO}_{2} \mathrm{O}_{5+\mathrm{x}}$ Single Crystals: A Cobalt Oxide with Square-Lattice $\mathrm{CoO}_{2}$ Planes Over a Wide Range of Electron and Hole DopingPhys.Rev B 2005, 71, 134414.

(35) Soda, M.; Yasui, Y. ; Fujita, T.; Miyashita, T.; Sato, M.; Kakurai, K. Magnetic Structures of High Temperature Phases of $\mathrm{TbBaCo}_{2} \mathrm{O}_{5.5}$ J. Phys. Soc. Jpn. 2003, 72,1729.

(36) Roy, S.; Dubenko, I. S.; Khan, M. ; Condon, E. M.; Craig, J.; Ali, N.; Liu, W.; Mitchell, B. S. Magnetic Properties of PerovskiteDerived Air-synthesized $\mathrm{RBaCo}_{2} \mathrm{O}_{5+\delta}(\mathrm{R}=\mathrm{La}, \mathrm{Ho})$ compounds Phys. Rev. B 2005, 71, 024419.
(37) Karen, P.; Woodward, P. M. Synthesis and Structural Investigations of the Double Perovskites $\mathrm{REBaFe}^{2} \mathrm{O}_{5+\mathrm{w}}(\mathrm{RE}=\mathrm{Nd}$, Sm)J. Mater.Chem. 1998, 9, 789.

(38) Elzubair, A.; El Massalami, M.; Domingues, P. H. On the Structure and Magnetic Properties of the Series $\mathrm{RBa}_{2} \mathrm{Fe}_{3} \mathrm{O}_{8+x}$ ( $\mathrm{R}=\mathrm{La}, \mathrm{Nd}, \mathrm{Sm}, \mathrm{Gd})$ Physica B: Condensed Matter 1999, 271, 284.

(39) Karen, P.; Woodward, P.; Santhosh, P.; Vogt, T.; Stephens, P. W.; Pagolay, S. Verwey Transition under Oxygen Loading in $R \mathrm{BaFe}_{2} \mathrm{O}_{5+w}(R=\mathrm{Nd}$ and $\mathrm{Sm}) J$. Solid State Chem. 2002, 167, 480.

(40) Moritomo, Y.; Hanawa, M.;. Ohishi, Y ; Kato, K.; Nakamura, J.; Karppinen, M.; Yamauchi, H. Physical Pressure Effect on the Charge-Ordering Transition of $\mathrm{BaSmFe}_{2} \mathrm{O}_{5.0}$ Phys. Rev. B 2003, 68 , 060101.

(41) Woodward, P. M.; Karen, P. Mixed Valence in $\mathrm{YBaFe}_{2} \mathrm{O}_{5}$ Inorg. Chem. 2003, 42, 1121-1129.

(42) Spiel, C.; Blaha, P.; Schwarz, K. Density functional calculations on the charge-ordered and valence-mixed modification of $\mathrm{YBaFe}_{2} \mathrm{O}_{5}$ Phys. Rev. B, 2009, 79, 115123.

(43) Lekse, J. W.;. Natesakhawhat, S. A; Matranga, C. An Experimental and Computational Investigation of the Oxygen Storage Properties of $\mathrm{BaLnFe}_{2} \mathrm{O}_{5+\delta}$ and $\mathrm{BaLnCo}_{2} \mathrm{O}_{5+\delta}(\mathrm{Ln}=\mathrm{La}, \mathrm{Y})$ Perovskites J. Mater. Chem. 2014, 2, 2397.

(44) Karen, P.; Kjekshus, A.; Huang, Q.; Lynn, J. W.; Rosov, N.; Sora, I. N.; Karen, V. L. ; Mighel, A. D.; Santoro, A. Neutron and XRay Powder Diffraction Study of $R \mathrm{Ba}_{2} \mathrm{Fe}_{3} \mathrm{O}_{8+w}$ Phases J. Solid State Chem. 1998, 136, 21.

(45) Huang, Q.; Karen, P.; Karen ,V. L.; Kjekshus, A.; Huang, Q.; Lynn, J. W.; Karen, V. L.; Mighell, A.D.; Rosov, N.; Santoro, A. Neutron-Powder-Diffraction Study of the Nuclear and Magnetic Structures of $\mathrm{YBa}_{2} \mathrm{Fe}_{3} \mathrm{O}_{8}$ at Room Temperature Phys. Rev. B 1992, 45,9611 .

(46) Karen, P.; Suard, E.; Fauth, F. Crystal Structure of Stoichiometric $\mathrm{YBa}_{2} \mathrm{Fe}_{3} \mathrm{O}_{8}$ Inorg. Chem. 2005, 44, 8170.

(47) Garcia-Gonzalez, E.; Parras, M.; Gonzalez-Calbet, J.M.; Vallet-Regi, M. A New "123" Family: $L n \mathrm{Ba}_{2} \mathrm{Fe}_{3} \mathrm{O}_{z}$ : I. $L N=$ Dy, Ho $J$. Solid State Chem. 1993, 104, 232.

(48) Collins, C.; Dyer, M.S.; Demont, A.; Chater, P.A.; Thomas, M.F.; Darling, G.R.; Claridge, J.B.; Rosseinsky, M.J. Computational Prediction and Experimental Confirmation of B-site Doping in $\mathrm{YBa}_{2} \mathrm{Fe}_{3} \mathrm{O}_{8}$ Chemical Science 2014, 5, 1493.

(49) Volkova, N. E.; Lebedev, O.I.; Gavrilova, Y.L.; Turner, S.; Seikh, M.M.; Gauquelin, N.; Caignaert, V.; Cherepanov, V.A.; Raveau, B.; Van Tendeloo, G. Nanoscale Ordered Oxygen Deficient Quintuple Perovskite Sm2- $\varepsilon \mathrm{Ba} 3+\varepsilon F e 5 \mathrm{O} 15-\delta$. Chem. Mat. 2014, 26, 6303.

(50) Kundu, A. K.; Lebedev, O.I.; Volkova, N. E.; Caignaert, V.; Seikh, M.M.;. Cherepanov, V.A; Raveau, B. Quintuple Perovskites Ln2Ba3Fe5-xCoxO15- $\delta$ : Nanoscale Ordering and Unconventional Magnetism J. Mat. Chem. C 2015, 3, 5398 .

(51) Kundu, A.K.;. Mychinko, M.Y ; Caignaert, V.; Lebedev, O.I.;. Volkova, N.E; Deryabina, K.M.; Cherepanov, V.; Raveau, B. Quintuple Perovskite Phasoids in the system $\mathrm{Nd}_{2-\varepsilon} \mathrm{Ba}_{3+\varepsilon}(\mathrm{Fe}, \mathrm{Co})_{5} \mathrm{O}_{15-\delta}$ J.Solid State Chem. 2015, 231, 36-41

(52) Linden, J.; Karen, P.; Kjeshus, A.; Miettinen, J. ; Karppinen, M. Partial Oxygen Ordering in Cubic Perovskite $R E \mathrm{Ba}_{2} \mathrm{Fe}_{3} \mathrm{O}_{8+w}(R E=\mathrm{Gd}, \mathrm{Eu}, \mathrm{Sm}, \mathrm{Nd}) J$. Solid State Chem. 1999, 144, 398.

(53) Huang, Q.; Karen, V. L.; Santoro, A.; Kjekshus, A.; Linden, J.; Karen, P. Substitution of $\mathrm{Co}^{3+}$ in $\mathrm{YBa}_{2} \mathrm{Fe}_{3} \mathrm{O}_{8} J$. Solid State Chem. 2003, 172, 73 
Table of Contents (TOC)

Exceptional Layered Ordering of Cobalt and Iron in Perovskites.

Oleg I.Lebedev, Stuart Turner, Vincent Caignaert, Vladimir A. Cherepanov, and Bernard Raveau

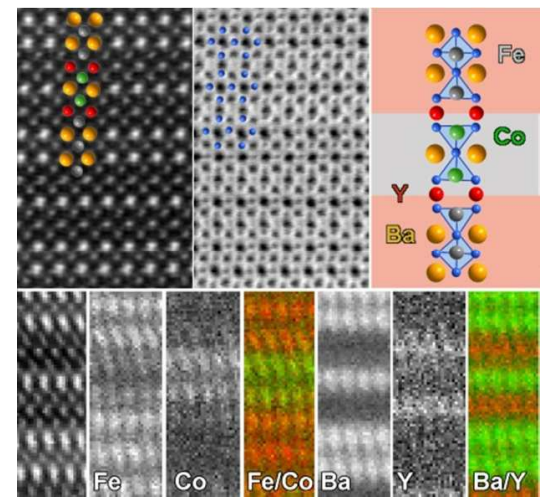

19

20

21

22

23

24

25

26

27

28

29

30

31

32

33

34

35

36

37

38

39

40

41

42

43

44

45

46

47

48

49

50

51

52

53

54

55

56

57

58

59

60 